Article

\title{
Effect of Side Chain Functional Groups on the DPPH Radical Scavenging Activity of Bisabolane-Type Phenols
}

\author{
Kazuya Ichikawa, Ryosuke Sasada, Kosuke Chiba and Hiroaki Gotoh * $\mathbb{D}$ \\ Department of Chemistry and Life Science, YOKOHAMA National University, 79-5 Tokiwadai, Hodogaya-ku, \\ Yokohama 240-8501, Japan; ichikawa-kazuya-ym@ynu.jp (K.I.); sasada-ryosuke-cy@ynu.jp (R.S.); \\ chiba-kosuke-dh@ynu.jp (K.C.) \\ * Correspondence: gotoh-hiroaki-yw@ynu.ac.jp
}

Received: 31 January 2019; Accepted: 11 March 2019; Published: 16 March 2019

\begin{abstract}
Methods for improving the antioxidant activity of phenolic compounds have been widely investigated; however, most studies have focused on the structure-activity correlations of substituents on the aromatic rings of catechols or flavonoids. We investigated the influence of side chain functional groups on the 2,2-diphenyl-1-picrylhydrazyl (DPPH) radical scavenging activity of xanthorrhizol and curcuphenol analogues. These compounds were synthesised by the side chain functional group conversion of curcumene, followed by direct oxidation of the aromatic ring. We determined the DPPH radical scavenging activity from the half-maximal effective concentration $\left(\mathrm{EC}_{50}\right)$ obtained from a DPPH assay in methanol. The positional relationships of the side chain with the aromatic ring and phenolic $\mathrm{OH}$ group were determined using density functional theory calculations, and the stability of different conformations was compared. Electron transfer-proton transfer was determined to be the dominant mechanism in the DPPH reaction with xanthorrhizol analogues, based on the correlation between the $\mathrm{EC}_{50}$ and ionisation potential. The radical cation was greatly stabilised in the structure where the side chain functional group was close to the aromatic ring. Stabilisation also depended on the phenolic $\mathrm{OH}$ group position. In future antioxidant design, aromatic ring substituent conversion and the use of functional groups far from the $\mathrm{OH}$ group or ring should be explored.
\end{abstract}

Keywords: curcuphenol; electron proton transfer; phenols; sesquiterpenes; xanthorrhizol

\section{Introduction}

Some of the oxygen taken into a living body by respiration is converted into reactive oxygen species (ROS), which are considered to contribute to cancer and aging due to the damage they cause to nucleic acids, lipids, and proteins [1,2]. Phenolic compounds are well known for reducing and detoxifying ROS [3,4] through a hydrogen atom transfer mechanism (HAT, Equation (1)) [5], a single electron transfer mechanism (electron transfer-proton transfer, ET-PT, Equation (2)) [6], or a sequential proton loss electron transfer mechanism (SPLET, Equation (3)) $[7,8]$. It has been shown that these radical scavenging activities of phenolic antioxidants are related to the phenolic $\mathrm{O}-\mathrm{H}$ bond dissociation enthalpy (BDE), ionization potential (IP), proton dissociation enthalpy (PDE), proton affinity (PA), and electron transfer enthalpy (ETE). It is therefore indispensable to study the structure-activity correlation and reduction mechanism of DPPH radicals of phenolic compounds in order to improve their DPPH radical scavenging activity.

$$
\begin{aligned}
& \mathrm{ArOH}+\mathrm{DPPH} \bullet \rightarrow \mathrm{ArO} \bullet+\mathrm{DPPH}-\mathrm{H} \\
& \mathrm{ArOH}+\mathrm{DPPH} \bullet \rightarrow \mathrm{ArOH}{ }^{+}+\mathrm{DPPH}^{-}
\end{aligned}
$$




$$
\begin{aligned}
\mathrm{ArOH} \bullet & +\mathrm{DPPH}^{-} \rightarrow \mathrm{ArO} \bullet+\mathrm{DPPH}-\mathrm{H} \\
\mathrm{ArOH} & \rightarrow \mathrm{ArO}^{-}+\mathrm{H}^{+} \\
\mathrm{ArO}^{-}+\mathrm{DPPH} \bullet & \rightarrow \mathrm{ArO} \bullet+\mathrm{DPPH}^{-}
\end{aligned}
$$

Electronic factors for improvements to the antioxidant activity of catechols and benzylphenols have been studied with DPPH [9] assays and computational chemistry using analogues with new substituents on the aromatic ring [10]. A comprehensive structure-activity correlation by substituent conversion of phenolic and aniline compounds has recently been reported [11]. Intramolecular interactions due to substituents adjacent to phenolic $\mathrm{OH}$ groups as reaction sites have also been found to contribute to the stabilisation of intermediates, as exemplified by studies with catechols $[12,13]$. Moreover, it has been established that antioxidant behaviour cannot be fully rationalized unless interactions with the surrounding medium are carefully considered. The role of the side chain in antioxidant activity has also been studied previously, considering its importance in the polarity, mobility, and localisation of the antioxidant [14].

Phenolic natural products with a bisabolane-type sesquiterpene skeleton [15-17] (Figure 1) have been isolated from marine sponge organisms and fern plants, and have various antioxidant activities, depending on the substitution position of the phenolic $\mathrm{OH}$ group or the type of functional group on the side chain. In a study of the suppression of the production of lipid peroxide using rat brain homogenate as a reaction field, curcuphenol showed moderate activity, of the 11 tested phenolic metabolites extracted from marine invertebrates. However, curcudiol, a compound with an $\mathrm{OH}$ group on the side chain, had the highest antioxidant activity [18]. Moreover, in the evaluation of the antioxidant activity in cells using a cell permeable fluorescent probe (DCFH-DA), curcudiol showed activity while curcuphenol did not [19]. It has been confirmed in other compounds such as hydroquinones that antioxidant activity greatly changes when an $\mathrm{OH}$ group is present on the side chain [20]. Xanthorrhizol (1) has drawn attention from drug discovery researchers [21] because it has numerous beneficial physiological activities such as neuroprotective ability [22], lipid peroxidation inhibitory ability (antioxidant ability [22,23]), and antibacterial ability [24,25]. Acetylation of the phenolic $\mathrm{OH}$ in xanthorrhizol (1) reduces its physiological activity, strongly suggesting that the phenolic $\mathrm{OH}$ group is involved in the physiological activity mechanism [22-24]. The influence of functional groups on the side chain, such an $\mathrm{OH}$ group, has not been studied for xanthorrhizol (1) analogues.<smiles>CC(C)=CCCC(C)c1ccc(C)c(O)c1</smiles>

xanthorrhizol

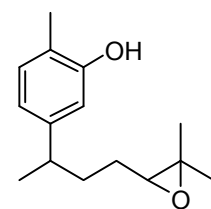

12,13-epoxyxanthorrhizol

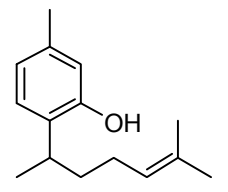

curcuphenol

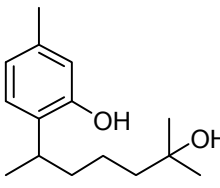

curcudiol

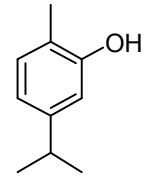

carvacrol

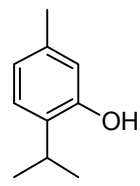

thymol

Figure 1. Bisabolane-type sesquiterpenoids and similar phenols from natural products.

Evaluation of the antioxidant activity of compounds such as xanthorrhizol (1) has been carried out using DPPH assays and lipid peroxide suppression reactions [21-24]. Analytical evaluation of compounds with different side chain functional groups in the same skeleton showed a difference in antioxidant activity, but the influence of the side chain on a compound's antioxidant activity has rarely been discussed. If the influence of the side chain functional group on the compound's antioxidant activity can be clarified, that information would be very useful in the molecular design of new antioxidants.

In this study, curcumene, which can be synthesised in two steps from inexpensive reagents, was used as a starting substrate. After converting the side chain, aromatic ring oxidation by phthaloyl peroxide was performed to synthesise multiple analogues, especially xanthorrhizol (1) analogues, which are relatively more difficult to synthesise than curcuphenol analogues. In order to investigate the 
influence of the side chain on the DPPH radical scavenging activity, the synthesised analogues, as well as commercially available carvacrol and thymol, which do not have side chains, were evaluated by DPPH assays. We also clarified the influence that the side chain has on the reduction mechanism based on the correlation between thermodynamic parameters obtained by density functional theory (DFT) calculations and DPPH assay values. There is no prior research that has used theoretical calculations to evaluate the effect of side chain functional groups on the DPPH radical scavenging activity of curcumene derivatives; however, discussions based on experimental results and calculations can be expected in the future development of such research.

\section{Materials and Methods}

\subsection{Synthesis}

Compounds with bisabolane-type sesquiterpene skeletons were synthesised by side chain conversion from curcumene, which can be synthesised using the reported methods, followed by direct oxidation of the aromatic rings using phthaloyl peroxide [26]. Side chain conversion was used not only to synthesise olefins but also to append tertiary $\mathrm{OH}$, epoxy, and ketone groups.

\subsection{Measurement of $E_{50}$ with DPPH Assay}

DPPH radical scavenging activity was measured as described previously [27], with a slight modification. Each phenol was dissolved in methanol to make $5 \mathrm{~mL}$ of each solution, ranging in concentration from 0.10 to $5.60 \mathrm{mM}$. A solution of DPPH $(4.4 \mathrm{mg})$ in methanol $(4.41 \mathrm{~mL})$ was also prepared. The DPPH solution $(0.10 \mathrm{~mL})$ was added to each phenol solution, and after $30 \mathrm{~min}$, the absorbance of the mixtures and the blank was measured at $517 \mathrm{~nm}$ using a V-550 (cell length: $1 \mathrm{~cm}$ ) UV-Vis spectrophotometer (JASCO Corporation, Tokyo, Japan). From the change in absorbance (Abs) at $517 \mathrm{~nm}$, the reduction rate of each compound was calculated using the following formula:

$$
\text { Reduction rate }(\%)=\frac{\mathrm{Abs}_{\text {blank }}-\mathrm{Abs}_{\text {sample }}}{\mathrm{Abs}_{\text {blank }}} \times 100 \text {. }
$$

After plotting the reduction rate vs. concentration (SI), the half-maximal (50\%) effective concentration $\left(\mathrm{EC}_{50}\right)$ of each compound was calculated using a straight line taken from two points crossing the $50 \%$ reduction rate. As a model substrate, commercially available reagents without any side chains, thymol and carvacrol, were also evaluated using the same method.

\subsection{Theoretical Calculations}

A single-point calculation in methanol was carried out for the geometry at the (U)B3LYP/6-311+G** level. IEF-PCM was used to take the solvent effect into account. We used the most stable structure of each compound, charge and multiplicity, and distance feature to calculate the thermodynamic parameters.

To elucidate the influence of the side chain's functional groups on the DPPH radical scavenging activity of each synthesised compound, a conformation search of each synthesised compound in the neutral, radical, radical cation, and anion form was performed by molecular force field calculations using a Molecular Mechanics program 3 (MM3) [28,29]. Structures in which the functional groups on the side chain are close to the phenolic $\mathrm{OH}$ group or the aromatic ring, and one in which the functional groups on the side chain are far from them are defined as the initial structures. Energy was calculated using DFT calculations for 3-4 conformations in each case where the side chains were close and far. These structures were used to perform DFT calculation with the Gaussian 16 program [30]. Calculations were carried out at the (U)B3LYP/6-31G* level for gas-phase structural optimisation, and at the B3LYP/6-311+G** level with integral equation formalism-polarisable continuum models (IEF-PCM) [31] for the enthalpy of each compound in methanol. However, it should be noted that with the method using IEF-PCM, it is not possible to consider cases where hydrogen bonding occurs with 
solvent molecules. Using these calculation results, stability was compared based on the enthalpy when the side chains were close and far. Based on the enthalpy of each stable structure, five thermodynamic parameters, i.e., bond dissociation enthalpy (BDE), ionisation potential (IP), proton dissociation enthalpy (PDE), proton affinity (PA), and electron transfer enthalpy (ETE), were calculated using the following formulas. The BDE values were used to estimate the reactivity of an ArOH in HAT. The IP and PDE values from the $\mathrm{ArOH} \bullet^{+}$radical cation were calculated to describe the ET-PT mechanism. The PA values of the phenoxide anion, $\mathrm{ArO}^{-}$, were used to characterise the reaction enthalpy of the first step, and ETE for the reaction enthalpy of the following step in the SPLET mechanism. The values $\mathrm{H}\left(\mathrm{e}^{-}\right)=-19.85 \mathrm{kcal} / \mathrm{mol}$ and $\mathrm{H}\left(\mathrm{H}^{+}\right)=-246.6 \mathrm{kcal} / \mathrm{mol}$ were used as the enthalpies of protons and electrons in methanol, respectively [32-34]. The Winmostar program [35] was used to visualise each structure.

$$
\begin{gathered}
\mathrm{BDE}=\mathrm{H}(\mathrm{ArO} \bullet)+\mathrm{H}(\mathrm{H} \bullet)-\mathrm{H}(\mathrm{ArOH}) \\
\mathrm{IP}=\mathrm{H}(\mathrm{ArOH} \bullet \\
\mathrm{PDE}=\mathrm{H}(\mathrm{ArO} \bullet)+\mathrm{H}\left(\mathrm{e}^{-}\right)-\mathrm{H}\left(\mathrm{H}^{+}\right)-\mathrm{H}(\mathrm{ArOH}) \\
\mathrm{PA}=\mathrm{H}\left(\mathrm{ArO}^{-}\right)+\mathrm{H}\left(\mathrm{H}^{+}\right)-\mathrm{H}(\mathrm{ArOH}) \\
\mathrm{ETE}=\mathrm{H}(\mathrm{ArO} \bullet)+\mathrm{H}\left(\mathrm{e}^{-}\right)-\mathrm{H}\left(\mathrm{ArO}^{-}\right)
\end{gathered}
$$

\section{Results}

\subsection{Synthesis}

Six phenolic compounds with a bisabolane-type sesquiterpene skeleton, including three novel analogues (compounds 3, 5, and 6), were synthesised (Scheme 1). Xanthorrhizol (1) derivatives were predominantly synthesised over curcuphenol derivatives during the direct oxidation step. The regioselectivity of the oxidation was a result of a preferential reaction on the side with less steric hindrance, which concurs with a previous study [26]. Direct conversion from curcumene to xanthorrhizol was difficult as the olefin was oxidised earlier than the aromatic ring. For this reason, after the olefin was converted to a tertiary $\mathrm{OH}$, the aromatic ring was oxidised and the tertiary $\mathrm{OH}$ was converted back to an olefin. The commercially available compounds thymol and carvacrol, containing no side chains, were used as model substrates.

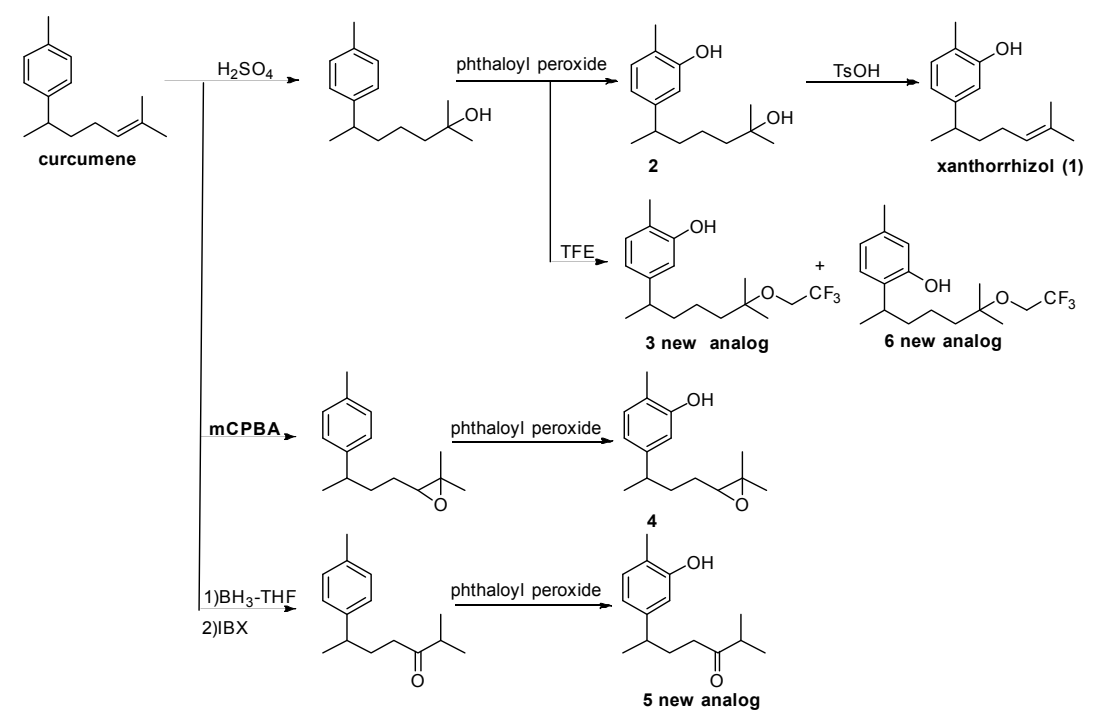

Scheme 1. Synthesis of bisabolane-type phenolic sesquiterpenes. TFE: 2,2,2-trifluoroethanol; mCPBA: m-chloroperoxybenzoic acid; IBX: 2-iodoxybenzoic acid; $\mathrm{BH}_{3}$-THF: borane-tetrahydrofuran complex. 


\subsection{Theoretical Calculations}

The enthalpy differences between the compounds, depending on whether the side chain functional group is in a close conformation or far conformation, are shown in Table 1. Compounds $\mathbf{1 - 5}$ tend to be more stable in a far conformation, with the exception of some of the radical cations, whereas the radical cation and anion of compound $\mathbf{6}$ are more stable in a close conformation. The five thermodynamic parameters determined from the DFT calculations are shown in Table 2, together with the $\mathrm{EC}_{50}$. Compound 6, containing the highest radical scavenging ability, exhibits low values for the BDE and ETE, and xanthorrhizol (1) has shown a low value for the IP.

Table 1. Enthalpies of the close conformation minus the far conformation ( $\mathrm{kcal} / \mathrm{mol})$.

\begin{tabular}{ccccc}
\hline Compounds & Neutral & Radical & Radical Cation & Anion \\
\hline xanthorrhizol (1) & +0.76 & +0.27 & -4.2 & +3.7 \\
$\mathbf{2}$ & +3.0 & +5.7 & -0.33 & +2.6 \\
$\mathbf{3}$ & +2.6 & +2.4 & -1.1 & +5.3 \\
$\mathbf{4}$ & +1.4 & +0.95 & +3.4 & +2.3 \\
$\mathbf{5}$ & +0.70 & +1.6 & +1.1 & +2.0 \\
$\mathbf{6}$ & +2.4 & +2.3 & -3.9 & -1.4 \\
\hline
\end{tabular}

Table 2. Thermodynamic parameters $(\mathrm{kcal} / \mathrm{mol})$ in methanol and DPPH radical scavenging ability $(\mu \mathrm{M})$

\begin{tabular}{ccccccc}
\hline Compounds & BDE & IP & PDE & PA & ETE & EC $_{\mathbf{5 0}}$ \\
\hline $\begin{array}{c}\text { xanthorrhizol } \\
(\mathbf{1})\end{array}$ & 79.6 & 114.3 & 12.5 & 49.9 & 76.9 & 817 \\
$\mathbf{2}$ & 79.2 & 118.8 & 7.6 & 49.5 & 76.9 & 1056 \\
$\mathbf{3}$ & 80.3 & 120.2 & 7.3 & 50.1 & 77.3 & 1156 \\
$\mathbf{4}$ & 79.7 & 118.6 & 8.3 & 50.3 & 76.6 & 1371 \\
$\mathbf{5}$ & 80.0 & 120.4 & 6.8 & 50.2 & 77.0 & 1579 \\
$\mathbf{6}$ & 78.3 & 119.4 & 6.1 & 50.6 & 74.9 & 531 \\
carvacrol & 79.6 & 118.8 & 8.0 & 49.2 & 77.6 & 1221 \\
thymol & 78.9 & 117.6 & 8.5 & 48.6 & 77.6 & 1073 \\
\hline
\end{tabular}

$\mathrm{BDE}$, bond dissociation enthalpy; IP, ionisation potential; PDE, proton dissociation enthalpy; PA, proton affinity; ETE, electron transfer enthalpy; $\mathrm{EC}_{50}$, half-maximal effective concentration.

\subsection{Measurement of $E C_{50}$ with DPPH Assay}

The results of the DPPH assay are shown in Table 2. Thymol had a higher radical scavenging ability than carvacrol, which is consistent with the results reported previously [36]. Compound 6 showed the highest radical scavenging ability. Xanthorrhizol (1) had the highest radical scavenging ability among the xanthorrhizol derivatives (compounds 1-5). Comparing compounds 3 and $\mathbf{6}$ showed that they had the same side chain functional groups but a different position of the phenolic $\mathrm{OH}$ group; however, the curcuphenol derivative 6 showed higher radical scavenging ability than compound 3 .

\section{Discussion}

\subsection{Influence of the Side Chain Functional Groups}

Correlations between each thermodynamic parameter and the $\mathrm{EC}_{50}$ were obtained for carvacrol and compounds $\mathbf{1}-\mathbf{5}$. The strongest positive correlation $\left(R^{2}=0.60\right)$ was that of IP (Figure 2). This suggests that IP, and therefore the ET-PT mechanism, is the largest contributor to the DPPH radical scavenging activity of these compounds. This agrees with a previous study that showed that phenolic compounds react through ET-PT mechanisms in polar solvents such as water and alcohols $[37,38]$. However, in the future, it should be noted that the substrate for generalisation and more accurate calculations need to be expanded in order to reduce uncertainty and errors. 


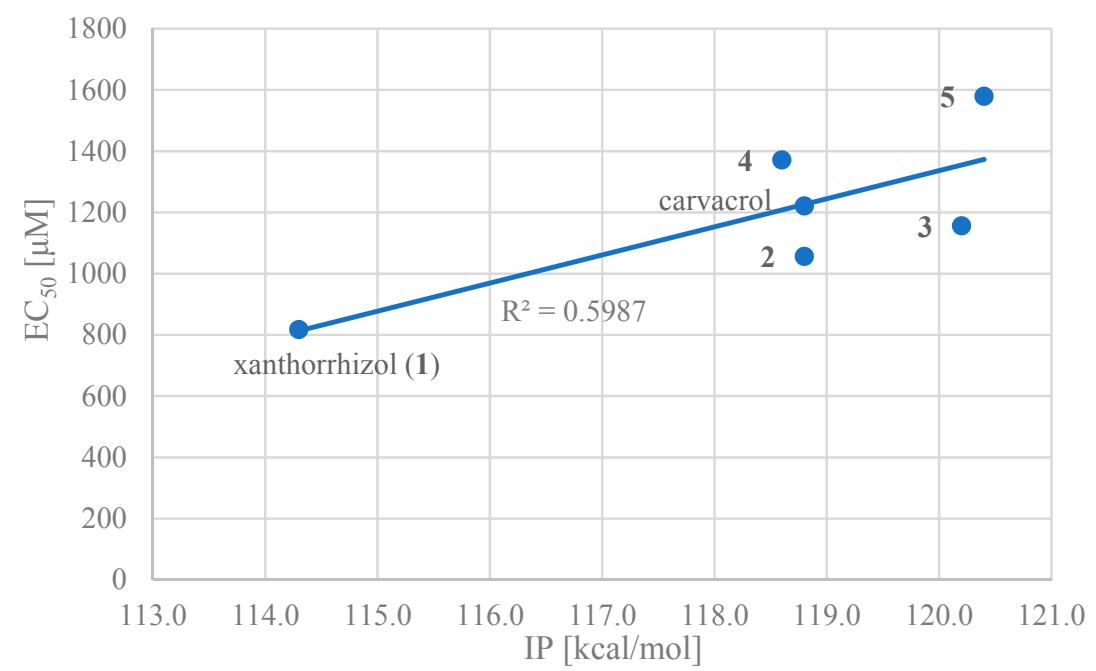

Figure 2. Half-maximal effective concentration $\left(\mathrm{EC}_{50}\right)$ vs. ionisation potential (IP) (compounds 1-5 and carvacrol).

In order to investigate the influence of the side chain on the DPPH radical scavenging activity, the thermodynamic stability of the neutral compound, the radical cation and the positional relationship of the side chain were determined. In the case of xanthorrhizol (1), which has a high radical scavenging ability and the smallest IP of compounds $\mathbf{1 - 5}$, the neutral compound is more thermodynamically stable when the side chain is in the far conformation, but the difference in stability compared to when the side chain is in close conformation is less than $1 \mathrm{kcal} / \mathrm{mol}$. Therefore, the conformation of the side chain does not have a notable influence on the neutral compound. Conversely, the radical cation is more stable when the side chain is in the close conformation, and there is a difference in energy of $4.2 \mathrm{kcal} / \mathrm{mol}$ compared with when the side chain is in the far conformation. Therefore, it is conceivable that the functional group on the side chain contributes to the stabilisation of the radical cation (Figure 3). As can be seen in the electron spin density of the radical cation, unpaired electrons are localised in the aromatic ring in the far conformation, whereas unpaired electrons are delocalised into the double-bond moiety on the side chain in the close conformation (Figure 4). In addition, the $\pi$ orbital of the aromatic ring is stabilised when the side chain is in the close conformation because electrons flow into the aromatic ring from the double-bond moiety of the electron-rich side chain, as can be seen in the orbital lobe diagram (Figure 5). It can therefore be inferred that xanthorrhizol (1) exhibited the smallest IP because of stabilisation of the radical cation through the double-bond moiety on the side chain, and as a result, had a higher radical scavenging ability. 


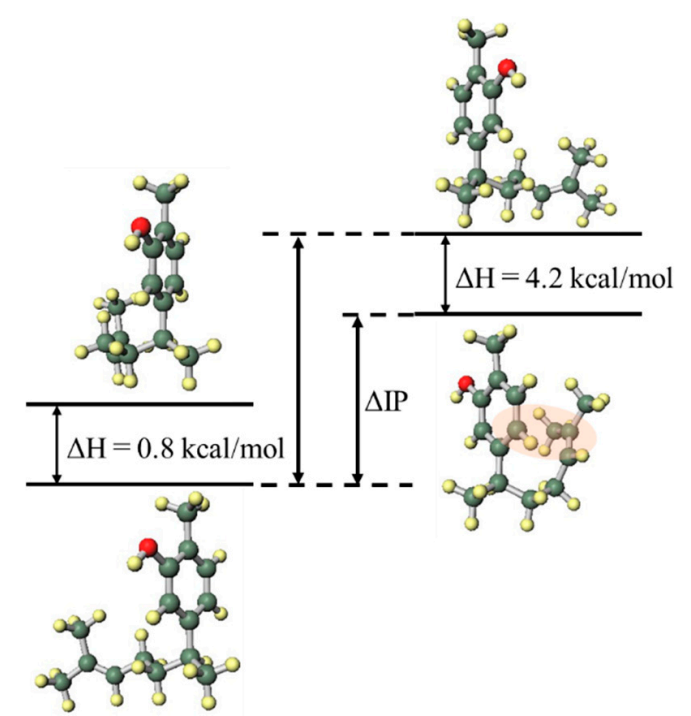

Figure 3. Neutral (left) and radical cation (right) energy diagrams of xanthorrhizol (1).
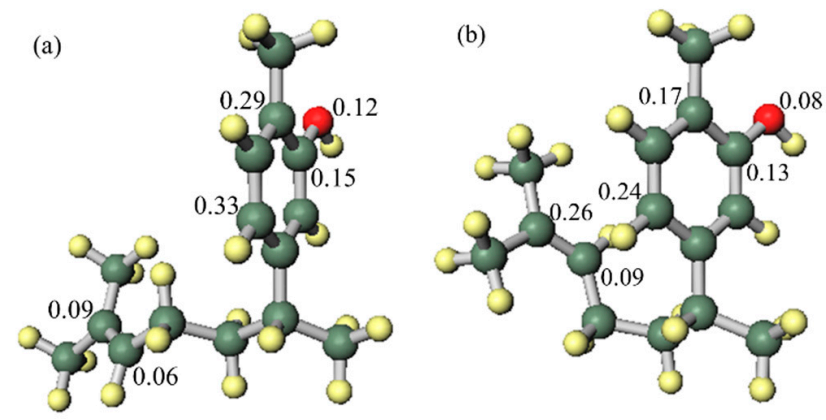

Figure 4. Spin density of the xanthorrhizol (1) radical cation: (a) far side chain conformation, (b) close side chain conformation.

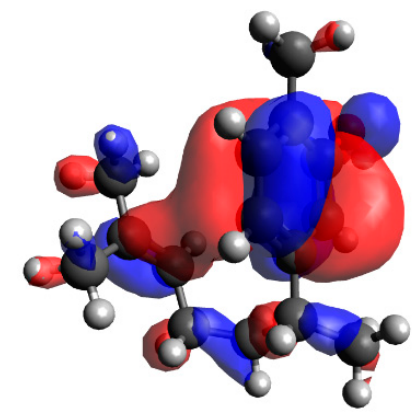

Figure 5. Molecular orbital lobe diagram of the xanthorrhizol (1) radical cation (next highest occupied molecular orbital).

\subsection{Influence of the Phenolic OH Group Position}

Carvacrol, thymol, and the new synthetic fluoro analogues 3 and $\mathbf{6}$ were compared in order to evaluate the influence of the phenolic $\mathrm{OH}$ group position. Compounds $\mathbf{3}$ and $\mathbf{6}$ had lower $\mathrm{EC}_{50}$ values than carvacrol and thymol, respectively. This suggests that the presence of the trifluoroethoxy group on the side chain improves the radical scavenging ability. When the functional group on the side chain was in the close conformation (Figure 6), the radical cation forms of compounds $\mathbf{3}$ and $\mathbf{6}$ were stable. However, there is a possibility that the mechanism may completely change due to competition between the groups on the side chains in their interactions, such as hydrogen bonding and intermolecular interaction, with solvent molecules $[39,40]$. However, intramolecular hydrogen bonding was observed by calculation using the IEF-PCM. Since the fluorine and oxygen atoms of the trifluoroethoxy group 
stabilised the radical cation by forming hydrogen bonds with the highly cationic hydrogen atom of the phenolic $\mathrm{OH}$ group and distortion did not occur, the close conformation was the most stable. This additional stability from the side chain functional group was the reason why compounds $\mathbf{3}$ and $\mathbf{6}$ had better $\mathrm{EC}_{50}$ values than carvacrol and thymol.
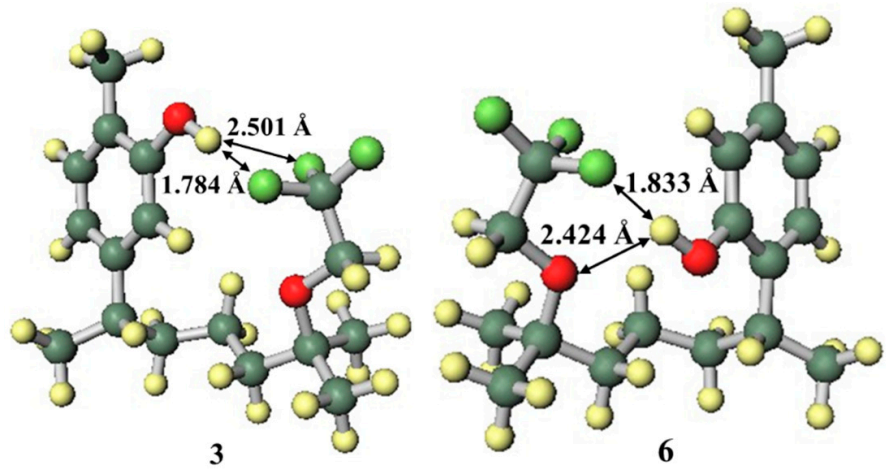

Figure 6. Structures of the radical cations of compounds 3 and $\mathbf{6 .}$

The difference in $\mathrm{EC}_{50}$ values between compounds 3 and $\mathbf{6}$ was larger than that between carvacrol and thymol. Since the side chain functional groups were the same for each pair, it can be inferred that the positional relationship between the phenolic $\mathrm{OH}$ group and the side chain was the cause of this difference. As can be seen in Table 1, while compound 3 was stabilised by a close trifluoroethoxy group on the side chain only for the radical cation, compound $\mathbf{6}$ had greater stabilisation for the radical cation and also had stabilisation by a close conformation side chain for the anion.

In the structure of the compound 3 anion (Figure 7a), where the side chain was in the close conformation (Figure $7 \mathrm{~b}$ ), hydrogen bonding between a phenolic oxygen atom with anionic properties and the highly acidic hydrogen atom of a methylene in the trifluoromethoxy group was expected to occur. This hydrogen bond would contribute to stabilisation; however, in compound 3, this hydrogen bond was formed with distortion generated in the side chain and aromatic ring. This caused destabilisation, and as a result, the far conformation was the more stable structure. In contrast, since the compound $\mathbf{6}$ anion can form a similar stabilizing hydrogen bond without distortion (Figure 8), the close conformation was the more stable structure. The fact that compound $\mathbf{6}$ was more likely than compound 3 to be found in an anionic state because of hydrogen bond stabilisation indicates the increased possibility of radical scavenging progressing through a SPLET mechanism $[5,39,40]$, which could be a factor in the good $\mathrm{EC}_{50}$ value of compound $\mathbf{6}$. To elucidate the mechanism in more detail, it will be necessary to further investigate curcuphenol analogues.
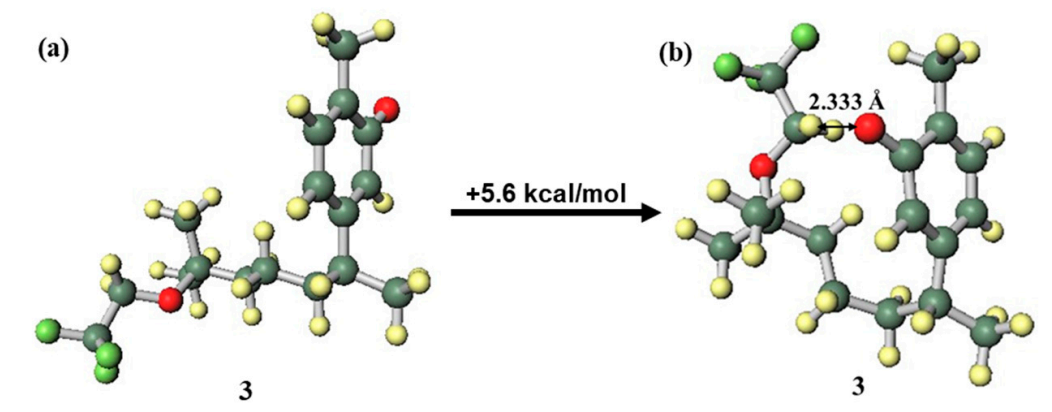

Figure 7. Difference in conformation stability of the compound 3 anion: (a) far conformation, (b) close conformation. 

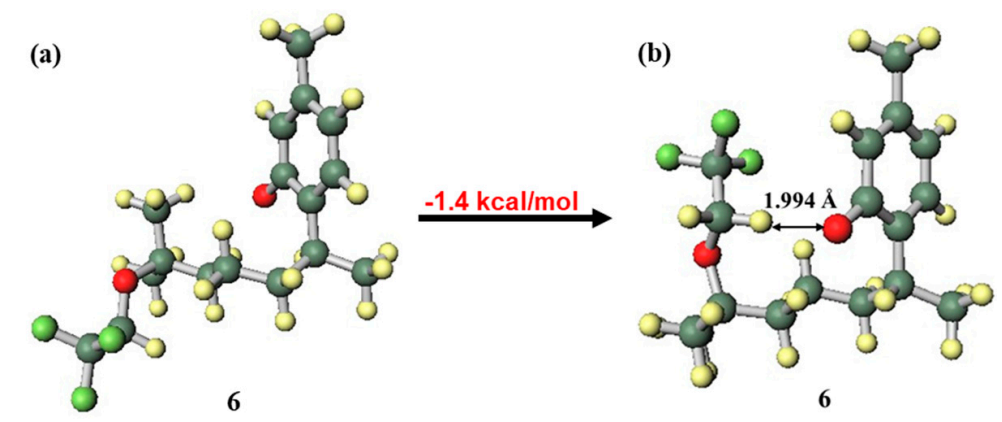

Figure 8. Difference in conformation stability of the compound 6 anion: (a) far conformation, (b) close conformation.

\section{Conclusions}

We synthesised bisabolane-type sesquiterpenoids and novel analogues, and investigated the influence of the side chain functional groups on the DPPH radical scavenging activity of these compounds using a DPPH assay and computer calculations. For compounds 1-5, the IP was the thermodynamic property that made the largest contribution to the radical scavenging ability, and as a result, the ET-PT mechanism was considered to be the dominant reduction mechanism. In addition, the positional relationship between the side chain and the aromatic ring or phenolic $\mathrm{OH}$ group was determined to be a cause of decreases in the IP value. A representative example of this is xanthorrhizol (1), which had a particularly small $\mathrm{EC}_{50}$ value, and was stabilised by the close conformation in the radical cation, and thus the electrons were delocalised due to the functional group on the side chain. Finally, the influence of the phenolic $\mathrm{OH}$ group position on the DPPH radical scavenging activity was investigated. It was determined that the magnitude of the stabilisation due to the interaction between the side chain functional group and the phenolic $\mathrm{OH}$ group, and the destabilisation due to the distortion of that structure greatly depended on the position of the phenolic $\mathrm{OH}$ group. In the case of compound $\mathbf{6}$, the stabilisation of the structure by the side chain in the anion led to the improvement of the radical scavenging ability through the SPLET mechanism. Based on these results, not only aromatic ring substituent conversion, but also the possibility of a new approach using functional groups far from the $\mathrm{OH}$ group or ring, should be investigated in future antioxidant designs. In the future, we would like to clarify the effects of the side chain by confirming the detailed solvent effect, using more accurate calculations, and measuring the antioxidant activity using methods close to the biological environment, while increasing the substrate range.

Author Contributions: All authors contributed to the project; the main contributions are specified as follows: conceptualization, K.I., R.S. and H.G.; methodology, K.I. and R.S.; validation, K.I. and R.S.; formal analysis, K.I. and R.S.; investigation, K.I., R.S. and K.C.; resources, H.G.; writing-original draft preparation, K.I.; writing一review and editing, K.I. and H.G.; visualization, K.I.; supervision, H.G.; project administration, H.G.; funding acquisition, H.G.

Funding: This research was supported by JSPS Grant-in-Aid for Young Scientists (B) Number 2681055.

Acknowledgments: We thank Kazuhisa Sakakibara for helpful discussions, and the Instrumental Analysis Center of YOKOHAMA National University for the use of their nuclear magnetic resonance (NMR) spectrometer. We would like to thank Editage (www.editage.jp) for English language editing.

Conflicts of Interest: The authors declare no conflict of interest.

\section{References}

1. Bolduc, J.A.; Collins, J.A.; Loeser, R.F. Reactive oxygen species, aging and articular cartilage homeostasis. Free Radic. Biol. Med. 2019, 132, 73-82. [CrossRef] [PubMed]

2. Kara, A.; Gedikli, S.; Sengul, E.; Gelen, V.; Ozkanlar, S. Oxidative stress and autophagy. In Free Radicals and Diseases; InTech Open: London, UK, 2016; pp. 69-86. 
3. Duthie, G.G. Determination of activity of antioxidants in human subjects. Proc. Nutr. Soc. 1999, 58, 1015-1024. [CrossRef] [PubMed]

4. Petrus, A.J.A. Biophenols: The abundant redox-active dietary molecules of life: A review. Asian J. Chem. 2014, 26, 4929-4939. [CrossRef]

5. Litwinienko, G.; Ingold, K.U. Solvent effects on the rates and mechanisms of reaction of phenols with free radicals. Acc. Chem. Rev. 2007, 40, 222-230. [CrossRef] [PubMed]

6. Galian, R.E.; Litwinienko, G.; Perez-Prieto, J.; Ingold, K.U. Kinetic solvent effects on the reaction of an aromatic ketone $\pi, \pi^{*}$ triplet with phenol. Rate-retarding and rate-accelerating effects of hydrogen-bond acceptor solvents. J. Am. Chem. Soc. 2007, 129, 9280-9281. [CrossRef]

7. Litwinienko, G.; Ingold, K.U. Abnormal solvent effects on hydrogen atom abstraction. 2. Resolution of the curcumin antioxidant controversy. The role of sequential proton loss electron transfer. J. Org. Chem. 2004, 69, 5888-5896. [CrossRef]

8. Litwinienko, G.; Ingold, K.U. Abnormal solvent effects on hydrogen atom abstraction. 3. Novel kinetics in sequential proton loss electron transfer chemistry. J. Org. Chem. 2005, 70, 8982-8990. [CrossRef]

9. Foti, M.C. Use and abuse of the DPPH• radical. J. Agric. Food Chem. 2015, 63, 8765-8776. [CrossRef]

10. Hussain, H.H.; Babic, G.; Durst, T.; Wright, J.S.; Flueraru, M.; Chichirau, A.; Chepelev, L.L. Development of novel antioxidants: Design, synthesis, and reactivity. J. Org. Chem. 2003, 68, 7023-7032. [CrossRef]

11. Horton, W.; Peerannawar, S.; Török, B.; Török, M. Theoretical and experimental analysis of the antioxidant features of substituted phenol and aniline model compounds. Struct. Chem. 2019, 30, 23-35. [CrossRef]

12. Amorati, R.; Valgimigli, L. Modulation of the antioxidant activity of phenols by non-covalent interactions. Org. Biomol. Chem. 2012, 10, 4147-4158. [CrossRef] [PubMed]

13. Menichetti, S.; Amorati, R.; Meoni, V.; Tofani, L.; Caminati, G.; Vaglianisi, C. Role of noncovalent sulfur $\cdots$ oxygen interactions in phenoxyl radical stabilization: Synthesis of super tocopherol-like antioxidants. Org. Lett. 2016, 18, 5464-5467. [CrossRef]

14. Niki, E. Assesment of antioxidant capacity in vitro and in vivo. Free Radic. Biol. Med. 2010, 49, 503-515. [CrossRef] [PubMed]

15. Park, J.-H.; Jung, Y.-J.; Mohamed, M.A.A.; Lee, T.H.; Lee, C.-H.; Han, D.; Song, M.-C.; Kim, J.; Baek, N.-I. New bisabolane sesquiterpenes from the rhizomes of Curcuma xanthorrhiza Roxb. and their inhibitory effects on UVB-induced MMP-1 expression in human keratinocytes. Helv. Chim. Acta 2014, 97, 438-446. [CrossRef]

16. Wright, A.E.; Pompon, S.A.; McConnell, O.J.; Kohmoto, S.; McCarthy, P.J. (+)-Curcuphenol and (+)-curcudiol, sesquiterpene phenols from shallow and deep water collections of the marine sponge Didiscus flavus. J. Nat. Prod. 1987, 50, 976-978. [CrossRef]

17. El Sayed, K.A.; Yousaf, M.; Hamann, M.T.; Avery, M.A.; Kelly, M.; Wipf, P. Microbial and chemical transformation studies of the bioactive marine sesquiterpenes (s)-(+)-curcuphenol and -curcudiol isolated from a deep reef collection of the Jamaican sponge Didiscus oxeata. J. Nat. Prod. 2002, 65, 1547-1553. [CrossRef] [PubMed]

18. Utkina, N.K.; Makarchenko, A.E.; Shchelokova, O.V.; Virovaya, M.V. Antioxidant activity of phenolic metabolites from marine sponges. Chem. Nat. Compd. 2004, 40, 373-377. [CrossRef]

19. Takamatsu, S.; Hodges, T.W.; Rajbhandari, I.; Gerwick, W.H.; Hamman, M.T.; Nagle, D.G. Marine natural products as novel antioxidant prototypes. J. Nat. Prod. 2003, 66, 605-608. [CrossRef] [PubMed]

20. Tziveleka, L.-A.; Kourounakis, A.P.; Kourounakis, P.N.; Roussis, V.; Vagias, C. Antioxidant potential of natural and synthesised polyprenylated hydroquinones. Bioorg. Med. Chem. 2002, 10, 935-939. [CrossRef]

21. Oon, S.F.; Nallappan, M.; Tee, T.T.; Shohaimi, S.; Kassim, N.K.; Sa'ariwijaya, M.S.F.; Cheah, Y.H. Xanthorrhizol: A review of its pharmacological activities and anticancer properties. Cancer Cell Int. 2015, 15, 100. [CrossRef] [PubMed]

22. Lim, C.S.; Jin, D.-Q.; Mok, H.; Oh, S.J.; Lee, J.U.; Hwang, J.K.; Ha, I.; Han, J.-S. Antioxidant and antiinflammatory activities of xanthorrhizol in hippocampal neurons and primary cultured microglia. J. Nuerosci. Res. 2005, 82, 831-838. [CrossRef] [PubMed]

23. Jantan, I.; Saputri, F.C.; Qaisar, M.N.; Buang, F. Correlation between chemical composition of Curcuma domestica and Curcuma xanthorrhiza and their antioxidant effect on human low-density lipoprotein oxidation. Evid. Based Complement. Alternat. Med. 2012, 2012, 438356-438365. [CrossRef] [PubMed] 
24. Hernández, D.M.; Díaz-Ruiz, G.; Rivero-Cruz, B.E.; Bye, R.A.; Aguilar, M.I.; Rivero-Cruz, J.F. Ent-trachyloban-19-oic acid isolated from Iostephane heterophylla as a promising antibacterial agent against Streptococcus mutans biofilms. Fitoterapia 2012, 83, 527-531. [CrossRef] [PubMed]

25. Aguilar, M.I.; Delgado, G.; Villarreal, M.L. New bioactive derivatives of xanthorrhizol. Rev. Soc. Quim. Mex. 2001, 45, 56-59.

26. Yuan, C.; Liang, Y.; Hernandez, T.; Berriochoa, A.; Houk, K.N.; Siegel, D. Metal-free oxidation of aromatic carbon-hydrogen bonds through a reverse-rebound mechanism. Nature 2012, 499, 192-196. [CrossRef]

27. Wang, S.-Q.; Zhu, X.-F.; Wang, X.-N.; Shen, T.; Xiang, F.; Lou, H.-X. Flavonoids from Malus hupehensis and their cardioprotective effects against doxorubicin-indused toxicity in H9c2 cells. Phytochemistry 2013, 87, 119-125. [CrossRef]

28. Allinger, N.L.; Yuh, Y.H.; Lii, J.-H. Molecular mechanics. The MM3 force field for hydrocarbons. 1. J. Am. Chem. Soc. 1989, 111, 8551-8566. [CrossRef]

29. Allinger, N.L. Molecular Structure: Understanding Steric and Electronic Effects from Molecular Mechanics; John Wiley \& Sons, Inc.: Hoboken, NJ, USA, 2010.

30. Frisch, M.J.; Trucks, G.W.; Schlegel, H.B.; Scuseria, G.E.; Robb, M.A.; Cheeseman, J.R.; Scalmani, G.; Barone, V.; Petersson, G.A.; Nakatsuji, H.; et al. Gaussian 16, Revision A.03; Gaussian, Inc.: Wallingford, CT, USA, 2016.

31. Lipparini, F.; Scalmani, G.; Mennucci, B.; Cancès, E.; Caricato, M.; Frisch, M.J. A variational formulation of the polarizable continuum model. J. Chem. Phys. 2010, 133, 014106. [CrossRef]

32. Rimarčík, J.; Lukeš, V.; Klein, E.; Ilčin, M. Study of the solvent effect on the enthalpies of homolytic and heterolytic N-H bond cleavage in $p$-phenylenediamine and tetracyano- $p$-phenylenediamine. Theochem 2010, 952, 25-30. [CrossRef]

33. Atkins, P.W. Physical Chemistry, 6th ed.; Oxford University Press: Oxford, UK, 1998.

34. Mejías, J.A.; Lago, S. Calculation of the absolute hydration enthalpy and free energy of $\mathrm{H}+$ and $\mathrm{OH}-$. J. Chem. Phys. 2000, 113, 7306. [CrossRef]

35. Winmostar Version 8; X-Ability Co. Ltd.: Tokyo, Japan, 2017.

36. Lin, C.-W.; Yu, C.-W.; Wu, S.-C.; Yih, K.-H. DPPH free-radical scavenging activity, total phenolic contents and chemical composition analysis of forty-two kinds of essential oils. J. Food Drug Anal. 2009, 17, 386-395.

37. Borgohain, R.; Guha, A.K.; Pratihar, S.; Handique, J.G. Antioxidant activity of some phenolic aldehydes and their diimine derivatives: A DFT study. Comput. Theor. Chem. 2015, 1060, 17-23. [CrossRef]

38. Hamlaoui, I.; Bencheraiet, R.; Bensegueni, R.; Bencharif, M. Experimental and theoretical study on DPPH radical scavenging mechanism of some chalcone quinoline derivatives. J. Mol. Struct. 2018, 1156, 385-389. [CrossRef]

39. Foti, M.C.; Daquino, C.; Geraci, C. Electron-transfer reaction of cinnamic acids and their methyl esters with the DPPH• radical in alcoholic solutions. J. Org. Chem. 2004, 69, 2309-2314. [CrossRef] [PubMed]

40. Litwinienko, G.; Ingold, K.U. Abnormal solvent effects on hydrogen atom abstraction. 1. Reactions of phenols with 2,2-diphenyl-1-picrylhydrazyl (dpph•) in alchols. J. Org. Chem. 2003, 68, 3433. [CrossRef] [PubMed]

(C) 2019 by the authors. Licensee MDPI, Basel, Switzerland. This article is an open access article distributed under the terms and conditions of the Creative Commons Attribution (CC BY) license (http://creativecommons.org/licenses/by/4.0/). 